\title{
LCM-UFRGS Research Group Report: What are we doing in Computer Music?
}

\author{
Marcelo S. Pimenta ${ }^{1}$, Rodrigo Schramm ${ }^{2}$, Marcelo Johann ${ }^{1}$ \\ ${ }^{1}$ Instituto de Informática, UFRGS \\ Caixa Postal 15064 - 90501-970 Porto Alegre, RS \\ ${ }^{2}$ Departamento de Música, UFRGS \\ \{mpimenta,johann\}@inf.ufrgs.br ; rschramm@ufrgs.br
}

\begin{abstract}
In this paper, we present a historical overview and a brief report of the main recent activities at LCM (Laboratório de Computação Musical) of UFRGS (Universidade Federal do Rio Grande do Sul).

\section{Introduction}

LCM (Laboratorio de Computação Musical) is a multidisciplinary Computer Music research laboratory at UFRGS.

Permanent members of LCM are Marcelo Johann e Marcelo Pimenta (Informatics Institute, UFRGS) e Rodrigo Schramm (Music Department, UFRGS). We have also partners from others institutions from Brazil and around the world like Eduardo Miranda (University of Plymouth, UK) and Eloy Fritsch (Music Department, UFRGS), Evandro Miletto (Instituto Federal do Rio Grande do Sul - IFRS), Luciano V. Flores (QI Technology Faculty) e Leandro Costalonga (Universidade Federal do Espírito Santo - UFES), the last four partners having worked during MSc or-and $\mathrm{PhD}$ at LCM.

As with any multidisciplinary team, our work reflects the background and interests of group members, together or individually. In this article, we will first describe the history of the LCM and in the following section, we present a summary of recent works at LCM.
\end{abstract}

\section{LCM: a little bit of history}

Officially, the Computer Music research at LCMUFRGS began in 1994 at the Institute of Informatics, mainly related to works on Artificial Intelligence and Music, with Eloi Fritsch and Fabio Beckenkamp. Soon, the team integrated IC students, masters and doctoral students, making the group growing in size and importance. The LCM group has been present since the first Brazilian Symposiums on Musical Computation - SBCM and is one pioneer of the area in Brazil.

After completing his $\mathrm{PhD}$ thesis in Computer Music at the UFRGS Computer Science graduate program in 2002, Eloi Fritsch became a lecturer of Electronic Music at the Department of Music of UFRGS and started to implement the Electronic Music Center (Centro de Música Eletrônica - $\mathrm{CME}$ ) of the Arts Institute of UFRGS. The CME provides three electroacoustic music labs with the most advanced features for computer composition. Research and extension teams at $\mathrm{CME}$ prepared a series of acousmatic music concerts with the UFRGS speaker orchestra, presenting compositions in different theatres and auditoriums of the university.

In 1998, Marcelo Pimenta joined UFRGS and the LCM. Soon afterwards came Marcelo Johann and more recently Rodrigo Schramm. The profile of our permanent members is a sample of how much we value diversity. In recent years we have had excellent partners such as Marcelo Queiroz (University of São Paulo - USP), Flavio Schiavoni (Universidade Federal de São João del Rei UFSJ) and the partners of the Ubiquitous Music group (see Section 3.2 below), Maria Helena de Lima, Victor Lazzarini (National University of Ireland, Maynooth) and Damián Keller (Universidade Federal do Acre - UFAC). The LCM has successfully achieved international credibility, being part of important collaborative projects and being honoured with the opportunity to host the International Conference on New Interfaces for Musical Expression - NIME 2019.

\section{LCM recent works}

The main motivation of the team is the creation of computer-based support for creativity. Creativity plays a crucial role in culture. Creative activities provide personal, social, and educational benefit, but creativity takes different forms at different times and in different places. For Plato, and later for the Romantics, for instance, creativity was an attribute (a gift) of certain mysteriously favored individuals. Today's consensus favors the view that creativity can be developed through education and opportunity that it can be an attribute of teams and groups as well as individuals, and that its social, cultural, and technological contexts matter [62].

Because of the breadth of use to which artists put different forms of digital technology, and because they typically are not steeped in conventional information technology approaches, artists' perspectives on tools and applications may provide valuable insights into the needs of other kinds of users of digital technology, that would not be obvious in a more narrowly focused technological context. Conversely, outcomes of computer science 
research may challenge artists to rethink their established assumptions and practices.

To a software developer, it might seem that the keys to technology-based creative practices are simply equipment and software- developing and providing access to standard, commercial IT tools for artists. This perspective is useful as far as it goes, and it can provide a good way to get started with IT, but in the long run, it is an insufficiently rich or flexible one. "We make our tools; then our tools make us", we can claim, inspired by Marshall McLuhan [75].

Technology-based creative practices can constitute an important domain of research. It is inherently exploratory and inherently transdisciplinary. Concerned at its core with how people perceive, experience, and use information technology, it pushes on the boundaries of both digital technology and arts. In transdisciplinary research, the point is not just application of given methodologies but also a result of imagining entirely new possibilities for what disciplines can do.

\subsection{Music creation by novices}

Traditionally music composition process - for both composers and songwriters - assumes taking in account some musical knowledge (music theory, musical forms, techniques and skills in instrument playing and so on) and adopting some (either conventional or not) music notation to represent the music resulting of such process.

For novices, we prefer the generic term "music creation", and the only thing we can assume for a music creation process by novices is that we can make no assumptions about a novice's skills or knowledge. So, a simple replication of musician-oriented concepts, interfaces, symbols and features, without a careful analysis of their requirements and world views, could result in tools that would seem useless and unusable to these novice users. We intend to provide any user-either experienced musicians or not - access to meaningful and engaging musical experiences. Thus, we focus less on the musical quality of the finished work and more on the rich and flexible support for the music creation.

In previous work [79], we have proposed, discussed and illustrated some principles for music creation by novices in networked music environments: (1) music creation by novices should be prototypical; and (2) music creation by novices should be cooperative. These principles have emerged during CODES [76] design and development. CODES is a Web-based networked music environment designed to support cooperative ways of music creation by novices [77]. Some mechanisms and concepts related to the principle \#2 - music creation by novices should be cooperative - can be found in [80].

Principle \#1 is particularly interesting for guiding technology-based artistic creation by novices as a Design activity [73]. A design activity can be guided by cyclical prototypes construction where experimentation is not only allowed but also stimulated as well. Prototype creation allows designers to identify the error (or parts that are most likely to have problems), solve those errors/problems and then continue the creation, leading to unexpected discoveries and innovations that may or may not take the project beyond its initial scope. Prototypes are thus used to continuously revise and expand the design.

Design activity needs iteration (due its cyclic nature) and interaction design, taking ideally less time and effort to build prototypes. Indeed, the goal of interaction design is to create products that enable the user to achieve their objective(s) in the best way possible [82]. If this definition sounds broad, that's because the field (Interaction Design and User Experience Design) is rather broad: the interaction between a user and a product often involves elements like aesthetics, motion, sound, space and much more. And the User Experience (UX) Design refers to shaping the experience of using a product, and most part of that experience involves some interaction between user and the product.

In our previous work CODES, creation of music prototypes was made possible by means a good interaction design, a visual notation with icons for representing sound and music, and direct manipulation metaphor for manipulating such icons [15,16,78]. Recently, this interface between Computer Music and Human-Computer Interaction (HCI) was called musical interaction design, having as goal "to bridge models and tools from both domains by combining recent developments, and providing a musical interaction design workbench to facilitate the exploration and definition of new interactive technologies for both musical creation and performance" [84].

From this perspective, the work of Evandro Miletto first in the master's degree [8] and later in the doctorate [7] - investigated how networked music technology can provide adequate support for music creation and to discuss how it is possible to overcome a set of natural barriers and to define requirements specifically oriented to user novices in music. As the testbed of this research it was developed an environment for cooperative musical creation on the web, CODES [3,7,8,10,18,19, 47,48,49,50,51]. CODES (COoperative Musical Prototypes DESign) is a web-based environment designed and developed to allow cooperative musical experimentation by novices in order to turn them creators of musical content. Evandro is now a lecturer at IFRS and continues to do research in this environment. Many master's and undergraduate studies were carried out in the context of CODES - [14, 48, 54], such as the works of Aurélio Hoppe, Felipe Scheeren and Guilherme Testa.

\subsection{Ubiquitous Music}

We have proposed the adoption of the term ubiquitous music $[12,69]$ (or simply ubimus) to promote practices that empower participants of musical experiences through socially oriented, creativityenhancing tools [28]. To achieve this goal, our group has been engaged in a multidisciplinary effort to investigate the creative potential of converging forms of social interaction, mobile and distributed technologies and innovative music-making practices.

Recently, the tendency for major increase in processing power, and convergence of technologies in everyday, ubiquitous consumer mobile devices has attracted the interest of several computer music researchers and artists. They saw the potential of 
combining music and mobile devices - something that is already being called mobile music [67] — in experiments that involve supporting mobility intrinsic to musicians, distributed and instant access to musical information and processing, design of new instruments (like [63]), new forms of audience participation and collaboration, localisation and context awareness (as in locative audio) and connectivity for musical activities [61, 68].

One of our goals is to develop tools which take advantage of these inclusive contexts, providing conditions to novices to participate in creative activities, ideally in any place and at any moment. Our strategy, for this, relies on repurposing everyday consumer mobile devices (devices they already own, and are familiar with) as ubiquitous music interfaces for use in musical activities, taking benefit from their distinctive capabilities of portability, mobility, and connectivity and above all from their availability to the average person (including novices in music) [35]. In fact, the smartphone has become the emblematic figure of ubiquitous computing and of Ubiquitous Music: it is the most popular and ubiquitous computing device that ever existed. Breaking such barrier that keep novices away from artistically expressing themselves, the next challenge is to investigate how to provide support for such artistic activities in a way they can be carried out even by people with little or no previous artistic knowledge.

This work started as a $\mathrm{PhD}$ thesis theme by Luciano Vargas Flores - An Infrastructure for the Design of Musical Interaction with Daily Mobile Devices [6]. Luciano's thesis was an exploratory research that investigated the possibilities and elements involved in the use of consumer mobile devices as tools for musical activities. Common mobile information and communication devices - mobile phones, smartphones and handheld computers - have increasingly incorporated functionality through the convergence phenomenon and tend to become generic mobile computing platforms. The related existing works presented specific solutions, requiring a proposal for the organization of general concepts and the basis for interaction design in this area. From the point of view of the Human-Computer Interaction area, a central problem in this context is how to perform the interaction design of a system for musical activities involving non-specific mobile devices, that is, devices were not originally designed for musical tasks. This is what we identify in this work as the problem of "device reuse" (device repurposing). The solution involves not modifying the devices, but rather finding their own and varied (alternative) ways of manipulating data and musical information using the features already on the devices. In addition, the design of musical interaction should not only consider the instrumental paradigm - based on the interaction with traditional musical instruments - but rather include in the design space other interaction paradigms, many of them originated and already adopted in the area of Computer Music. In his work, these various paradigms or forms of musical interaction were identified and formalized as proto-patterns of interaction. The collection and refinement of the patterns was possible through an exploratory methodology based on the experience of developing several mobile musical prototypes, which also included an extensive bibliographic review and the analysis of existing systems. The result of this process was organized in the form of an infrastructure composed of concepts and principles, interaction patterns and tools to support the design of interactive musical systems involving mobile consumer devices.

When we started working and exchanging ideas about this theme $[35,36,30,40,29,45]$, soon more partners emerged, and we formed a multidisciplinary and multi-institutional and international group (called gubimus). The meetings of this research group have been held since 2010 in the form of a workshop - Ubimus Workshop on Ubiquical Music, but which seems to have become effectively international: the VI Ubimus was held in Sweden (2015- Växjö) and the near Ubimus workshop will be a satellite event of the CMMR conference, to be held in France now in 2019. The repercussion of the group's work has been great and culminated with the publication of a book by Springer in 2014, called Ubiquitous Music [12], and of which Marcelo Pimenta is one of the editors.

More recently, in collaboration with Leandro Costalonga (UFES), we are investigating biological and cognitive principles for the adoption of musicality in the conception of Computer Music systems and tools and non-conventional instruments (DMIs, Digital Music Instruments).

\subsection{Music Information Retrieval (MIR)}

The LCM group have also integrated techniques based on Music Information Retrieval (MIR) into its research portfolio. Over the last decade, the growing number of machine learning algorithms have also motivated the development of new tools for automatic music understanding and music creation.

Multi-pitch detection is an essential task for the development of automatic music transcription systems. Algorithms based on spectrogram factorization have been investigated by the LCM team and applied to automatic music transcription of audio recordings of a cappella performances with multiple singers [58]. The research on this topic has been boosted with the implementation of a collaborative project started in 2016, connecting faculty members from Queen Mary University of London, University of Edinburgh and UFRGS. In the scope of this collaboration, we have proposed a system for multi-pitch detection and voice assignment that integrates an acoustic and a music language model. The acoustic model performs spectrogram decomposition, extending Probabilistic Latent Component Analysis (PLCA) using a 6-dimensional dictionary with pre-extracted log-spectral templates. The music language model performs voice separation and voice assignment using hidden Markov models that apply musicological assumptions. The system was evaluated with audio recordings of polyphonic vocal music, being able to detect multiple concurrent pitches and assign each detected pitch to a specific voice type such as soprano, alto, tenor or bass (SATB). A paper with results of this research received the Best Paper Award at the AES International Conference on Semantic Audio, Erlangen [59].

Variants of our PLCA based algorithm for multi- 
pitch detection were explored to build alternative tools for automatic transcription of musical instruments, as the diatonic harmonica and the electric guitar.

Since methods based on spectrogram factorization may suffer from local-optima issues in the presence of harmonic overlap or considerable timbre variability, we proposed [56] a set of harmonic constraints that are inherent to the Harmonica instrument note layout or are caused by specific diatonic Harmonica playing techniques. These constraints help to guide the factorization process of the PLCA based algorithm to meaningful convergence, resulting in better estimates of multi-pitch activations. This research is in progress, and it will make available a new audio dataset containing solo recordings of diatonic Harmonica excerpts and the respective multi-pitch annotations.

Aiming to support the creative musical process, the LCM team has integrated the MIR research with the development of new interfaces for musical expression (NIME). Such development has as premises the timbre replacement of acoustic instruments and also the possibility to use it as an embedded system. These two premises aim to address the rapid instrument augmentation, and the entire system was designed to run on a low-cost embedded computer, suitable for live performance and easy to customize for different use cases. A prototype is described in [57], where the core of the system implements real-time spectrum factorization, decomposing polyphonic audio input signals into music note activations. We have successfully implemented our system for the augmentation of electric guitars, where the timbre replacement is achieved by applying the extracted polyphonic pitch activations to mix a variety of synthetic or sampled sounds into the output audio signal.

\subsection{Digital sound synthesis on low-cost platforms}

Microcontrollers and other integrated processors have evolved significantly not only in terms of technology but also in their availability and easy of

use. One reference milestone, for instance, is the Arduino project, which helped to popularize simple standard microcontroller boards as well as a standard programming IDE.

At first such readily available low-cost boards were very easy to use for simple projects but lacked performance for more sophisticated DSP tasks such as audio synthesis and processing, because they employed 8-bit microprocessors without even hardware multiplications in 16 bits. But in the last years, several alternatives emerged using 32-bit cores with higher clock rates and integrated resources, with single cycle 32-bit hardware multiplication, such as the Arduino Due, Teensy 3.6, ESP32, for example.

In such processors, several interesting audio applications can be implemented, with standard highquality sample rates and bit depths, external ADCs and DACs. It is important to note that this is still a much simpler and lower cost solution compared to the processing power available on integrated single board computers and mobile phones, which, by their turn, are still below a typical computational performance of a desktop or server processor, as show in table 1.

\begin{tabular}{|l|l|}
\hline \multicolumn{1}{|c|}{ Platform / Processor } & \multicolumn{1}{c|}{ Speed } \\
\hline Intel Core i7 & $\sim 3,5$ GFLOPs/core \\
\hline Qualcomm Snapdragon 810 (Sony Xperia Z5) & $\sim 1,45$ GFLOPs/core \\
\hline Raspberry Pi 3 & $\sim 180$ MFLOPs/core \\
\hline Arduino Due & 1,11 MFLOPs (float) \\
\hline Arduino Uno & 0,089 MFLOPs (float) \\
\hline
\end{tabular}

Table 1

Nevertheless, it might go unnoticed that the computing power used to implement several digital synthesizers and effect processors of the first generations in the past was also very modest. The flagship DX7 digital FM synthesizer from Yamaha was one of the highest selling synthesizers in history and together with other products they made the FM synthesis technology to be the second most profitable patent for the Stanford University before it expired. Its hardware sound generation engine used two custom VLSI circuits with fixed point arithmetic and a single hardware adder. Not even a multiplier was needed, as the developers wisely used exponent addition to represent multiplication and table-based conversions between linear values and their logarithms.

In other words, with current low-cost microcontroller boards, it is possible to implement several fully functional digital synthesizers and processors. We have been experimenting with a few basic instruments as a starting point. Firstly, an additive synthesizer was implemented [86], what showed that an organ with full 61-notes polyphony and 9 harmonics per key can be implemented on the $84 \mathrm{MHz}$ Arduino Due, with external 16-bit DAC and basic amplitude and pitch modulations. After that, two other synthesizers were implemented. The first one is an FM synthesizer with the same resources as the original FM DX7, however restricted to only 6 notes of polyphony. The second one was a subtractive synthesizer composed of two oscillators using band limited audio generating algorithms, one digital resonant filter and two envelopes [85, 88]. There are other implementations in the same line, such as [87], and we believe that such works must be promoted.

Although it is common to implement standard well known processes such as additive, subtractive, FM synthesis, sample playback (or ROMplers), it is worthwhile to note that the true value of such readiness to implement audio processes lies one its potential to innovate, making custom instruments, new synthesis algorithms, to employ novel parameters and controllers, to integrate music intelligence with sound generation and so on.

The design of alternative digital instruments has been addressed by integrating the computational resources of smartphones. The SIBILIM project [60] is a low-cost musical interface built on a resonance box made of cardboard containing customized push buttons with no electronic circuit. Sound generation is provided by an external smartphone that interacts with the push buttons through its video camera. Each button is tracked in realtime by the mobile application, and the user controller is mapped to a set of MIDI notes or control parameters. The sound is generated through synthesis or sample playback 
and can be amplified with the help of a transducer, which excites the resonance box. The embedded computer vision algorithm allows the rapid reconfiguration of the buttons' layout with no need for hard rewiring to any electronic circuit. These features allow for quick instrument customization for different use cases, such as low-cost projects for schools or instrument building workshops. Our case study used the SIBILIM for music education, where it was designed to develop the consciousness of music perception and to stimulate creativity through exercises of short tonal musical compositions.

\section{Final Considerations}

One of the challenges of the LCM group is the exploratory investigation of how to integrate digital technology into research and artistic creativity (including multimodal sound, music, and image interactions) through theories, concepts, principles, technologies and tools with the goal of investigating the creative potential of converging forms of social interaction, mobile and distributed technologies, and materially grounded artistic practices.

In this paper, we presented a historical overview, the team and a brief report of the activities of the LCM (Laboratório de Computação Musical) of UFRGS. The lab started in pioneer times, and the team has today turned into a potential group of researchers from partner institutions in Brazil and abroad, carrying out studies connecting music and technology beyond the frontiers of the knowledge, and placing a high value on creativity.

However, some questions remain open, as for example: what can be done with technology - integrating research and art, and also adopting new paradigms of interaction - to provide support to the creativity of ordinary people? What kind of experience does this suggest? And what kinds of behavior of creation and listening? Are mobile devices good generic platforms for integrating digital technology with research and artistic creativity as they are good as interactive music performance devices? These questions and others, which arise every day, motivate the continuity of studies in the LCM.

\section{References}

[1] Honing, H.: The origins of musicality. The MIT Press, Cambridge, Massachusetts, USA (2018)

[2] Creativity-centred design for ubiquitous musical activities: Two case studies. Journal of Music, Technology and Education., v.5, p.195 - 222, 2012.

[3] Interfaces for Musical Activities and Interfaces for Musicians are not the Same: The Case for CODES, a Web-based Environment for Cooperative Music Prototyping. Intl Conf. on Multimodal Interfaces, 2007.

[4] Pimenta, M. et al.. Ubiquitous Music: A Manifesto, Prologue of Book Ubiquitous Music. Springer, ISSN 1868-0305, 2014.
[5] Pimenta, M. S.; Miletto, E.M.; Flores, L.V.; HOPPE, A. F. Cooperative mechanisms for networked music. Future Generation Computer Systems, v.27, p.100 - 108, 2011.

[6] Flores, L. V.. Uma infraestrutura para o design da interação musical com dispositivos móveis cotidianos. 2014. Tese (doutorado) - UFRGS/PPGC, Porto Alegre, 2014.

[7] Miletto, E. M.. CODES: an interactive noviceoriented web-based environment for cooperative musical prototyping. 2009. Tese (doutorado) - UFRGS/PPGC, Porto Alegre, 2009.

[8] Miletto, E. M.; Pimenta, M. S.; Vicari, R. M.; Flores, L. V.: CODES: a web-based environment for cooperative music prototyping. In: Organised Sound, Cambridge Vol.10, n. 3 (2005), p. 243-253, il.

[9] Pinheiro da Silva, F.; Keller, D.; Silva, E. F.; Pimenta, Marcelo S.; Lazzarini, V.. Criatividade Musical Cotidiana: Estudo Exploratório de Atividades Musicais Ubíquas. Música Hodie, v. 13, p. 64-79, 2013.

[10] Miletto, E. M.; Pimenta, M.; Bouchet, F.; Sansonnet, J-P.; Keller, D.. Principles for Music Creation by Novices in Networked Music Environments. Journal of New Music Research, v. 40:3, p. 205-216, 2011.

[11] Keller, D.; Flores, L. V.; Pimenta, M.; Capasso, A.; Tinajero, P.. Converging Trends Toward Ubiquitous Music. Journal of New Music Research, v. 40:3, p. $265-$ 276, 2011

[12] Keller, D.; Lazzarini, V.; Pimenta, M. S.: Ubiquitous music. Cham: Springer, c2014. xxviii, 153 p., il. (Computational music science).

[13] Fritsch, E. F.; Flores, L. V.; Miletto, E. M.; Vicari, R. M.; Pimenta, M. S.: Software musical e sugestões de aplicação em aulas de música. In: Ensino de música: propostas para pensar e agir em sala de aula. São Paulo: Moderna, 2003. p. 141-157.

[14] Pimenta, M. S.; Keller, D.; Miletto, E.; Flores, L. V.; Testa, G. G.. Technological Support for Online Communities Focusing on Music Creation: Adopting Collaboration, Flexibility and Multiculturality from Brazilian Creativity Styles. In: Azab, Nahed Amin. (Org.). Cases on Web 2.0 in Developing Countries. 1ed.Hershey, USA: IGI Global, 2013, v., p. 283-312.

[15] Miletto, E. M.; Pimenta, M. S.; Sansonnet, J.-P.; Bouchet, F.: Social music making on the web with CODES. In: Annual ACM Symposium on Applied Computing (25.: 2010 Mar.: Sierre, Switzerland). Proceedings of the 2010 Annual ACM Symposium on Applied Computing. Danvers: ACM, c2010. p. 876-877.

[16] Miletto, E. M.; Pimenta, M. S.; Hoppe, Aurelio F.; Flores, L. V.: Who are the web composers? In: International Conference on Online Communities and Social Computing (3.: 2009 July: San Diego, CA). Proceedings, Berlin: Springer, c2009 p. 381-390.

[17] Hoppe, A. F.; Miletto, E. M.; Flores, L V.; Pimenta, M. S.: Cooperation in musical prototypes design. In: 
International Conference on Computer Supported Cooperative Work in Design (13.: 2009 April: Santiago, Chile). Proceedings, New York: IEEE, c2009. p. 698703.

[18] Miletto, E. M.; Pimenta, M. S.; Vicari, R. M.: Using Codes cooperative music prototyping and educational perspectives. In: International Computer Music Conference (2005 Sept.: Barcelona). Conference proceedings.: SuviSoft OY, 2005. p. 387-390, il.

[19] Miletto, E. M.; Pimenta, M. S.; Costalonga, L. L.; Vicari, R. M.: Using the web-based cooperative music prototyping environment CODES in learning situations. In: Intelligent tutoring systems. ITS proceedings of the 7. International Conference on Intelligent Tutoring Systems 2004, Maceió (Lecture notes in computer science, v. 3220), p. 833-835.

[20] Keller, D.; Silva, F. P. da; Giorni, B.; Pimenta, M. S.; Queiroz, M.: Marcação espacial: estudo exploratório. In: Simpósio Brasileiro de Computação Musical (13.: 2011 ago 31-03 set.: Vitória, ES). Anais do $13^{\circ}$ Simpósio Brasileiro de Computação Musical [recurso eletrônico]. Porto Alegre: SBC, 2011. [12] f., il.

[21] Radanovitsck, E. A. A.; Keller, D.; Flores, L. V.; Pimenta, M. S.; Queiroz, M.: MixDroid: marcação temporal para atividades criativas. In: Simpósio Brasileiro de Computação Musical (13.: 2011 ago 31-03 set.: Vitória, ES). Anais do $13^{\circ}$ Simpósio Brasileiro de Computação Musical. Porto Alegre: SBC, 2011.

[22] Flores, L. V.; Pimenta, M. S.; Miranda, E. R.; Radanovitsck, E. A. A.; Keller, D.: Patterns for the design of musical interaction with everyday mobile devices. In: Simpósio de Fatores Humanos em Sistemas Computacionais (9.: 2010 out: Belo Horizonte, BR-MG). Anais [recurso eletrônico]. [S.1.]: Sociedade Brasileira de Computação, [2010?]. p. 121-128.

[23] Flores, L. V.; Miletto, E. M.; Pimenta, M. S.; Miranda, E. R.; Keller, D.: Musical interaction patterns: communicating computer music knowledge in a multidisciplinary project. In: ACM International Conference on Design of Communication SIGDOC (28.: 2010 Sept. 27-29: São Carlos, BR-SP). Proceedings of the 28th ACM International Conference on Design of Communication. New York: ACM, c2010. p. 199-206, il.

[24] Miletto, E. M.; Flores, L. V.; Pimenta, M. S.; Santagada, L.; Jerome, R.: Interfaces for Musical Activities and Interfaces for Musicians are not the Same: The Case for CODES, a Web-based Environment for Cooperative Music Prototyping. In: The Ninth International ACM Conference on Multimodal Interfaces (ICMI 2007), 2007, Nagoya, Japan. Proceedings of Ninth International ACM Conference on Multimodal Interfaces (ICMI 2007). New York: ACM Press, 2007. v. 1. p. 201207. (ICMC), 2010.

[25] Keller, D.; Pinheiro da Silva, F.; Giorni, B.; Pimenta, M. S.; Queiroz, M.: Marcação Espacial: Estudo Exploratório In: 13 Simpósio Brasileiro de Computação Musical (SBCM 2011), 2011, Vitória. Anais do Simpósio Brasileiro de Computação Musical (pen drive). Porto Alegre: SBC, 2011. v.1. p.1 - 30.
[26] Radanovitsck, E. A. A.; Keller, D.; Flores, L.; Pimenta, Marcelo S.; Queiroz M.: mixDroid: marcação temporal para atividades criativas. In: Simpósio Brasileiro de Computação Musical, SBCM 2011, 2011, Vitória. Anais do Simpósio Brasileiro de Computação Musical (pen-drive). Porto Alegre: SBC, 2011. v.1.

[27] Yi, S.; Lazzarini, V.; Timoney, J.; Keller, D.; Pimenta, M. S. The mobile Csound platform. In: International Computer Music Conference ICMC 2012, 2012, Ljubljana. Proceedings of International Computer Music Conference ICMC 2012. Ann Arbor: Ann Arbor, MI: MPublishing, University of Michigan Library 2012, 2012. v.2012.

[28] Keller, D.; Pinheiro da Silva, F.; Silva, E. F.; Lazzarini, V.; Pimenta, M. S.: Opportunistic Design of Ubiquitous Music Systems: the impact of anchoring as creativity support) (In Portuguese, Design oportunista de sistemas musicais ubíquos: O impacto do fator de ancoragem no suporte à criatividade. In: Proceedings of 14th Brazilian Symposium on Computer Music (SBCM 2013), 2013, Porto Alegre: SBC, 2013. v.1. p.1

[29] Keller, D.; Timoney, J.; Costalonga, L.; Capasso A.; Tinajero, P; Lazzarini, V.; Pimenta, M. S.; De Lima, M. H.; Johann, M.: Ecologically grounded multimodal design: the Palafito 1.0 study. In: Proc. of 40th International Computer Music Conference (ICMC 2014) joint with the 11th Sound \& Music Computing conference (SMC 2014)., 2014, Athens, Greece.

[30] Keller, D.; Otero, N.; Lazzini, V.; Pimenta, M. S.; Lima, M. H. de; Johann, M.; Costalonga, L.: Relational Properties in Interaction Aesthetics: The Ubiquitous Music Turn In: Electronic Visualisation and the Arts 2014, 2014.

[31] Keller, D.; Timoney, J.; Costalonga, L.; Capasso. A.; Tinajero, P.; Lazzarini, V.; Pimenta, M. S.; Lima, M. H. de; Johann, M.: Ecologically grounded multimodal design: the Palafito 1.0 study. In: Proceedings of 40th International Computer Music Conference (ICMC 2014) joint with the 11th Sound \& Music Computing Conference (SMC 2014), 2014, Athens, Greece.

[32] Behrendt, F.: From calling a cloud to finding the missing track: Artistic approaches to mobile music. In: 2nd International Workshop on Mobile Music Technology. Vancouver, Canada (2005)

[33] Carroll, J. (ed.) Creativity and Rationale - Enhancing Human Experience by Design Human-Computer Interaction Series, 2013, VIII, 456p. ISBN 978-1-44714110-5.

[34] Essl, G.; Rohs, M.: Interactivity for Mobile MusicMaking, Organised Sound 14(2): 197-207, 2009

[35] Flores, L.V., Pimenta, M.S., Keller, D.: Patterns for the design of musical interaction with everyday mobile devices. In: Proc. of the 9th Brazilian Symposium on Human Factors in Computing Systems. Belo Horizonte, Brazil (2010), 2010. v.1. p.41 - 50

[36] Flores, L.V.; Miletto, E. M.; Pimenta, M. S.; Miranda, E. R.; Keller, D.: Musical interaction patterns: communicating computer music knowledge in a 
multidisciplinary project. In: Proceedings of the 28th Annual International Conference on Design of Communication, SIGDOC 2010, Sao Carlos, ACM, 2010. p. $199-206$

[37] Flores, L.V.; Pimenta, M. S.; Miranda, E. R.; Radanovitsck, E. A.; Keller, D.: Patterns for the Design of Musical Interaction with Everyday Mobile Devices In: (IHC 2010) IX Brazilian Symposium on Human Factors in Computing Systems, 2010, Belo Horizonte, v.1. p.41 50

[38] Gaye, L.; Holmquist, L.E.: Mobile music technology: Report on an emerging community. In: NIME 06: Proceedings of the 2006 Conference on New Interfaces for Musical Expression, pp. 22-25 (2006)

[39] Holmquist, L.E.: Ubiquitous music. Interactions 12(4), $\quad 71$ ff. (2005).

http://doi.acm.org/10.1145/1070960.1071002

[40] Keller, D.; Flores, L.V.; Pimenta, M.; Capasso, A.; Tinajero, P.: Converging Trends Toward Ubiquitous Music. Journal of New Music Research, v. 40:3, p.265 276, 2011. [http://www.tandfonline.com/doi/pdf/10.1080/09298215. 2011.594514

[41] Keller, D.; Otero, N.; Lazzarini, V.; Pimenta, M. S.; Lima, M.H. de; Johann, M.; Costalonga, L.: Interaction Aesthetics and Ubiquitous Music In: Creativity in the Digital Age.1 ed. London: Springer London, 2015, v.1, p. 91-105. ISBN: 9781447166801 ,

[42] Keller, D.; Lazzarini, V.; Pimenta, M. S.: Ubiquitous Music. Heidelberg: Springer Intl. Publishing Switzerland, 2014, v.1. p.153.

[43] Keller, D.; Queiroz, M.; Barreiro, D.L.; Pimenta, M. S.: Anchoring in Ubiquitous Musical Activities In: International Computer Music Conference (ICMC), 2010, New York.

[44] Lazzarini,, V.; Keller, D.; Pimenta, M. S.: Prototyping of Ubiquitous Music Ecosystems. Journal of Cases on Information Technology., v.17, p.73 - 85, 2015.

[45] Lima, M.H.; Keller, D.; Pimenta, M.S.; Lazzarini, V.; Miletto, E.M.: Creativity-centred design for ubiquitous musical activities: Two case studies. J. Music Technol. Educ. 5(2), 195-222 (2012). doi:10.1386/jmte.5.2.195_1.

[46] McLuhan, M.; 1954, Notes on the Media as Art Forms. Explorations 2 (April): 6-13.

[47] Miletto, E. M.; Pimenta, M. S.; Vicari, R. M.; Flores, Codes, L.V.: a Web-based environment for cooperative music prototyping. Organised Sound (Print)., v.10, p.243 $-253,2005$.

[48] Miletto, E. M.; Pimenta, M.; Hoppe, A. F.; Flores, L.V.: Who Are the Web Composers? In: Proc. of 13th International Conference on Human-Computer Interaction (HCII 2009), 2009, San Diego, Berlin / Heidelberg: Springer, 2009. v.12. p.381 - 390

[49] Miletto, E.M.; Flores, L.V.; Pimenta, M.S.; Rutily, J.; Santagada, L.: Interfaces for musical activities and interfaces for musicians are not the same: The case for codes, a web-based environment for cooperative music prototyping. In: 9th International Conference on Multimodal Interfaces (ICMI), pp. 201-207. ACM, Nagoya (2007)

[50] Miletto, E.M.; Pimenta, M.S.; Bouchet, F.; Sansonnet, J.P.; Keller, D.: Principles for music creation by novices in networked music environments. J. New Music Res. 40(3), 205-216.

[51] Pimenta, M. S.; Miletto, E.M.; Flores, L.V.; Hoppe, A. F.: Cooperative mechanisms for networked music. Future Generation Computer Systems., v. 27, p.100 - 108, 2011.

[52] Pimenta, M.; Keller, D.; Lazzarini, V.: Prologue Ubiquitous Music: A Manifesto, In: Keller, D.; Lazzarini, V.; Pimenta, M. S.: Ubiquitous Music. Heidelberg: Springer Intl.Publishing Switzerland, 2014, v.1, p. 153

[53] Rogers, Y.; Sharp, H.; Preece, J.: Interaction Design - Beyond Human-Computer Interaction, Wiley, 3rd ed, 2011. ISBN 978-0-470-66576-3.

[54] Scheeren, F.; Pimenta, M. S.; Keller, D.; Lazzarini, V.: Coupling Social Network Services and Support for Online Communities in CODES Environment. In: 14th International Society for Music Information Retrieval Conference (ISMIR 2013), 2013, Curitiba.

[55] Wanderley, M. et al.: Human Computer Interaction meets Computer Music: The MIDWAY Project. Workshop Music and HCI, in conjunction with ACM CHI 2016, pp.4.

[56] Lins, F.; Johann, M.; E. Benetos; Schramm, R.: Automatic Transcription of Diatonic Harmonica Recordings, ICASSP, Brighton, UK, 12 May, 2019.

[57] Schramm, R.; Visi, F.; Brasil, A.; Johann, M.: A polyphonic pitch tracking embedded system for rapid instrument augmentation. NIME, Blacksburg, Virginia, USA, 4 Jun, 2018.

[58] Schramm, R.; McLeod, A.; Steedman, M; Benetos, E.: Multi-pitch detection and voice assignment for a capella recording of multiple singers. 18th International Society for Music Information Retrieval Conference, Suzhou, p552-559, 24 Oct, 2017.

[59] Schramm, R.; Benetos, E.: Automatic transcription of a cappella recordings from multiple singers. AES International Conference on Semantic Audio (BEST PAPER AWARD), Erlangen, 23 Jun, 2017.

[60] Nunes, H. de S.; Visi, F.; Coelho, L. H. W.; Schramm, R.: SIBILIM: a low-cost customizable wireless musical interface. NIME, Porto Alegre, 3 Jun, 2019.

[61] Behrendt, F.: From calling a cloud to finding the missing track: Artistic approaches to mobile music. In: 2nd International Workshop on Mobile Music Technology. Vancouver, Canada (2005)

[62] Carroll, J. (ed.): Creativity and Rationale Enhancing Human Experience by Design Human- 
Computer Interaction Series, 2013, VIII, 456p. ISBN 978-1-4471-4110-5.

[63] Essl, G.; Rohms, M.: Interactivity for Mobile MusicMaking, Organised Sound 14(2): 197-207, 2009

[64] Flores, L.V.; Pimenta, M.S.; Keller, D.: Patterns for the design of musical interaction with everyday mobile devices. In: Proceedings of the 9th Brazilian Symposium on Human Factors in Computing Systems. Belo Horizonte, Brazil (2010), 2010. v.1. p.41 - 50

[65] Flores, L.V.; Miletto, E. M.; Pimenta, M. S.; Miranda, E. R.; Keller, D.: Musical interaction patterns: communicating computer music knowledge in a multidisciplinary project In: Proceedings of the 28th Annual International Conference on Design of Communication, SIGDOC 2010, Sao Carlos, ACM, 2010. p.199 - 206

[66] Flores, L.V.; Pimenta, M. S.; Miranda, E. R.; Radanovitsck, E. A.; Keller, D.: Patterns for the Design of Musical Interaction with Everyday Mobile Devices In: (IHC 2010) IX Brazilian Symposium on Human Factors in Computing Systems, 2010, Belo Horizonte, v.1. p.41 50

[67] Gaye, L., Holmquist, L.E.: Mobile music technology: Report on an emerging community. In: NIME 06: Proceedings of the 2006 Conference on New Interfaces for Musical Expression, pp. 22-25 (2006)

[68] Holmquist, L.E.: Ubiquitous music. Interactions 12(4), $\quad 71 \quad$ ff. http://doi.acm.org/10.1145/1070960.1071002

[69] Keller, D.; Flores, L.V.; Pimenta, M.; Capasso, A.; Tinajero, P.: Converging Trends Toward Ubiquitous Music. Journal of New Music Research., v.40:3, p.265 276 ,

2011.

[http://www.tandfonline.com/doi/pdf/10.1080/09298215.

2011.594514

[70] Keller, D.; Otero, N.; Lazzarini, V.; Pimenta, M. S.; Lima, M.H.; Johann, M.; Costalonga, L.: Interaction Aesthetics and Ubiquitous Music In: Creativity in the Digital Age.1 ed.London : Springer London, 2015, v.1, p. 91-105. ISBN: 9781447166801,

[71] Keller, D.; Lazzarini, V.; Pimenta, M. S.: Ubiquitous Music. Heidelberg: Springer Intl. Publishing Switzerland, 2014, v.1. p.153.

[72] Keller, D.; Queiroz, M.; Barreiro, D.L.; Pimenta, M. S.: Anchoring in Ubiquitous Musical Activities In: International Computer Music Conference (ICMC), 2010, New York.

[73] Lazzarini,, V.; Keller, D.; Pimenta, M. S.: Prototyping of Ubiquitous Music Ecosystems. Journal of Cases on Information Technology., v.17, p.73 - 85, 2015.

[74] Lima, M.H.; Keller, D.; Pimenta, M.S.; Lazzarini, V.; Miletto, E. M.: Creativity-centred design for ubiquitous musical activities: Two case studies. J. Music Technol. Educ. 5(2), 195-222 (2012). doi:10.1386/jmte.5.2.195_1.

[75] McLuhan, M.: 1954, Notes on the Media as Art
Forms, Explorations 2 (April): 6-13.

[76] Miletto, E. M.; Pimenta, M. S.; Viccari, R. M.; Flores, L.V.: CODES: a Web-based environment for cooperative music prototyping. Organised Sound (Print)., v.10, p.243 - 253, 2005.

[77] Miletto, E. M.; Pimenta, M.; Hoppe, A. F.; Flores, L.V.: Who Are the Web Composers? In: Proc. of 13th International Conference on Human-Computer Interaction (HCII 2009), 2009, San Diego, Berlin / Heidelberg: Springer, 2009. v.12. p.381 - 390

[78] Miletto, E.M.; Flores, L.V.; Pimenta, M.S.; Rutily, J.; Santagada, L.: Interfaces for musical activities and interfaces for musicians are not the same: The case for codes, a web-based environment for cooperative music prototyping. In: 9th International Conference on Multimodal Interfaces (ICMI), pp. 201-207. ACM, Nagoya (2007)

[79] Miletto, E.M.; Pimenta, M.S.; Bouchet, F.; Sansonnet, J.P.; Keller, D.: Principles for music creation by novices in networked music environments. J. New Music Res. 40(3), 205-216. (2011). doi:10.1080/09298215.2011.603832

[80] Pimenta, M. S.; Miletto, E.M.; Flores, L.V.; Hoppe, A. F.: Cooperative mechanisms for networked music. Future Generation Computer Systems., v.27, p.100 - 108, 2011.

[81] Pimenta, M.; Keller, D.; Lazzarini, V.: Prologue Ubiquitous Music: A Manifesto, In: [11]

[82] Rogers, Y.; Sharp, H.; Preece, J.: Interaction Design - Beyond Human-Computer Interaction, Wiley, 3rd ed, 2011. ISBN 978-0-470-66576-3.

[83] Scheeren, F.; Pimenta, M. S.; Keller, D.; Lazzarini, V.: Coupling Social Network Services and Support for Online Communities in CODES Environment. In: 14th International Society for Music Information Retrieval Conference (ISMIR 2013), 2013, Curitiba.

[84] Wanderley, M. et al.: Human Computer Interaction meets Computer Music: The MIDWAY Project. Workshop Music and HCI, in conjunction with ACM CHI 2016, pp.4.

[85] Rodolfo P. P.; Johann, M.; Pimenta, M.: A modular platform for a subtractive synthesizer on Arduino Due. Proceedings of 15th Braziliam Symposium on Computer Music, 2015.

[86] Johann, M.: An additive synthesis organ with full polyphony on Arduino Due. VI Ubimus. Växjö, Linnaeus University, Sweden, 2015.

[87] Cyrille H.: OCS-2: A Digital, Semi Modular Synthesizer. $2017 . \quad$ Available at: <http://nozoid.com/ocs-2/>

[88] Rodolfo P. P.; Johann, M.; Pimenta. M.: Design and implementation of an open-source subtractive synthesizer on the Arduino Due platform. In: SBCM 2017. 